\title{
Pulmonary Vascular Distensibility and Lung Compliance as Modified by Dextran Infusion and Subsequent Atropine Injection in Normal Subjects*
}

\author{
Carlo Giuntini, $\dagger$ Attilio Maseri, and Romano Bianchi
}

(From the Center of Nuclear Medicine and Group of Clinical Physiology of the National Research Council, Institute of Medical Clinic, University of Pisa, Pisa, Italy)

Little information is available on the pressurevolume relationship of the human pulmonary circulation. Observations have been almost exclusively confined to limited groups of cardiac patients (1-6) in whom coexistence of extravascular alterations, such as interstitial perivascular edema $(7,8)$, may hinder the interpretation of the results. On the other hand, extrapolation to man of animal studies on the pressure-volume characteristics of the whole pulmonary vascular bed or part of it is not always warranted because of species variation and wide experimental differences. Finally, the combined evaluation of pulmonary vascular resistance and transmural pressure may provide information on the distensibility of resistive vessels but does not allow deductions on the distensibility of the pulmonary circulation as a whole, since the distribution of volume does not parallel that of resistance.

Previous reports have shown that the infusion of a plasma expander raised the pulmonary arterial and wedge pressures to the same extent (9); if the change in pressure was assumed to be practically uniform throughout the bed, such an infusion seemed to provide an opportunity to assess the compliance of the pulmonary vascular bed by determining the ratio of the change in volume to the change in pressure.

The values of the distensibility of the pulmonary circulation obtained with dextran infusion during the first studies were thought to be exceedingly low. We then decided to test some drug that could enhance the distensibility of the pulmonary vascular bed. Atropine sulfate, which was

\footnotetext{
* Submitted for publication June 8, 1966; accepted August 10, 1966.

This study was supported in part by the U. S. Atomic Energy Commission under contract AT(30-1)-2648.

$\dagger$ Address requests for reprints to Dr. Carlo Giuntini, General Medical Clinic, Ospedale S. Chiara, Pisa, Italy.
}

known to lower central venous pressure (10-15) and to be helpful in some types of pulmonary edema $(16,17)$, was found to produce a striking increase of the compliance of the lung circulation when injected intravenously in doses of 2 to $3 \mathrm{mg}$ after the infusion of dextran.

Since the behavior of the transpulmonary pressure in supine subjects after dextran infusion and atropine injection was unknown, we estimated this pressure in a separate group of subjects with the technic of the esophageal balloon, in order to assess its role in relation to the transmural vascular pressure. Finally, we performed determinations of dynamic and static lung compliances and lung volumes to ascertain the relationship between the distensibility of the pulmonary vascular bed and some mechanical properties of the lung.

\section{Methods}

\section{Pulmonary vascular distensibility}

Subjects. Seventeen subjects were selected for this study. Fifteen were cardiovascular normals, one had clinical and radiological evidence of pulmonary emphysema, and one had sinus bradycardia. The vital statistics and the diagnoses of the subjects are listed in Table I. Each of them gave informed consent to the experimental procedure.

Protocol. All subjects had a light meal not later than 3 hours before the study. They were catheterized in the recumbent position and received only Lugol's solution in preparation for the procedure. A no. 7 cardiac catheter was placed in the pulmonary artery for measuring pressures. A second catheter of the same size or smaller was introduced into the right atrium and utilized to inject radioiodinated human serum albumin (RIHSA).1 An indwelling arterial needle was placed in either a brachial or a femoral artery and was used to draw RIHSA dilution curves and to get blood samples. In six subjects a Teflon tube was inserted into the left ventricle via the femoral artery according to the technic described by Seldinger (18). In Subject 182 the Teflon

\footnotetext{
${ }^{1}$ Sorin, Saluggia, Vercelli, Italy.
} 
tube was positioned at the root of the aorta. Besides recording pressures, this catheter served the same purpose as the arterial needle. All the subjects were allowed to rest in the supine position for at least an hour. The study comprised a control period during which pulmonary arterial and wedge pressures and, in most instances, right atrial and ventricular and peripheral or aortic arterial pressures were recorded. In six subjects left ventricular pressure was also obtained. Blood flow was measured both from radiocardiograms (RCG) and arterial or left ventricular RIHSA dilution curves. The control period was followed by the infusion of $6 \%$ dextran in saline (macrodex). ${ }^{2}$ This solution is practically isotonic and isoviscous with respect to plasma and was prewarmed to body temperature. The infusion was made through a separate venous cannula, and it ranged from 1,000 to $1,500 \mathrm{ml}$ and lasted from 14 to 30 minutes. Pulmonary arterial, pulmonary wedge, and left ventricular pressures were recorded during the infusion. A few minutes after the end of the infusion all the measurements taken during the control period were repeated. In three subjects a third, and in two subjects a third and a fourth, set of measurements was performed long after the end of the infusion. In nine subjects 2 to $3 \mathrm{mg}$ of atropine sulfate was given intravenously, in seven after the first, and in two after the second, set of measurements after dextran. A few minutes after atropine a new set of measurements was taken; in four instances an additional set of measurements was taken at a fairly long time after atropine.

Plasma and total blood volume determinations. The control value of the plasma volume was obtained from

2 Don Baxter, Inc., Glendale, Calif. the plasma concentration of RIHSA 5 minutes after the injection for the control determination of cardiac output. An identical injection was made into a $1,000-\mathrm{ml}$ flask to measure the amount of RIHSA administered. Radioactive determinations were carried out with a well-type scintillation detector. Total blood volume (TBV) was calculated from plasma volume and hematocrit value corrected according to Chaplin, Mollison, and Vetter (19). Changes in plasma volume were measured both from the hematocrit and the control red cell mass corrected for the blood sampled and directly from the dilution of RIHSA injected for the determination of cardiac output. A comparison of the plasma volumes obtained with the two methods is plotted in Figure 1, A. There seems to be a small systematic difference, probably due to variation of the volume of the erythrocytes as suggested by the smaller reduction in the value of the hemoglobin than in that of the hematocrit after dextran infusion (Table II). Disregarding this small difference, we chose the plasma volume obtained from the hematocrit and the control red cell mass, since it showed less fluctuations in the successive measurements.

Cardiac output determination. Cardiac output was determined simultaneously with the same RIHSA injection from RCG and from arterial or left ventricular dilution curves. The details of the technic for obtaining RCG have already been published (20-23). The cylindrical collimator used for this study has an internal diameter of $5 \mathrm{~cm}$ and is $40 \mathrm{~cm}$ long. The $\mathrm{NaI}(\mathrm{T} 1)$ crystal $^{3}$ is also cylindrical with a diameter and a thickness of 3 inches. The combination of a large crystal with a relatively large and very long collimator provides a high

\footnotetext{
${ }^{3}$ Isomet Corp., Palisades Park, N. J.
}

TABLE I

Physical characteristics and diagnosis of the 17 subjects studied, amount of macrodex given, and duration of the infusion

\begin{tabular}{|c|c|c|c|c|c|c|}
\hline \multirow[b]{2}{*}{ Subject } & \multirow[b]{2}{*}{ Diagnosis } & \multirow[b]{2}{*}{ Sex } & \multirow[b]{2}{*}{ Age } & \multirow[b]{2}{*}{ BSA* } & \multicolumn{2}{|c|}{ Macrodex infusion } \\
\hline & & & & & Amount & Duration \\
\hline \multirow{19}{*}{$\begin{array}{l}154 \\
157 \\
158 \\
159 \\
161 \\
162 \\
167 \\
168 \\
171 \\
173 \\
182 \\
185 \\
187 \\
188 \\
192 \\
195 \\
207\end{array}$} & & & years & $m^{2}$ & $m l$ & $\min$ \\
\hline & Psychoneurosis & $\mathbf{M}$ & 35 & 1.80 & 1,000 & 22 \\
\hline & Duodenitis & $\mathbf{M}$ & 26 & 1.74 & 1,000 & 20 \\
\hline & Chronic tonsillitis & $\mathbf{M}$ & 16 & 1.74 & 1,000 & 21 \\
\hline & Nephrolithiasis & $\mathbf{M}$ & 35 & 1.94 & 1,000 & 17 \\
\hline & Sinus bradycardia & $\mathbf{M}$ & 18 & 1.98 & 1,000 & 16 \\
\hline & Mild pulmonary emphysema & $\mathbf{M}$ & 40 & 1.55 & 1,000 & 18 \\
\hline & Cervical osteoarthritis & $\mathbf{F}$ & 47 & 1.75 & 1,000 & 22 \\
\hline & Resolving cystitis & $\mathbf{M}$ & 39 & 2.06 & 1,000 & 15 \\
\hline & Resolving viral hepatitis & $\mathrm{F}$ & 29 & 1.52 & 1,000 & 20 \\
\hline & Lumbar neuralgia & $\mathbf{M}$ & 38 & 1.94 & 1,000 & 15 \\
\hline & Peripheral obliterating arteritis & $\mathbf{M}$ & 40 & 1.43 & 1,000 & 28 \\
\hline & Psychoneurosis & $\mathbf{M}$ & 27 & 1.72 & 1,000 & 14 \\
\hline & Resolving fibrinous pleuritis & $\mathbf{M}$ & 17 & 1.72 & 1,500 & 28 \\
\hline & Nephrolithiasis & $\mathbf{M}$ & 27 & 1.80 & 1,000 & 16 \\
\hline & Duodenal ulcer & $\mathbf{M}$ & 43 & 1.82 & 1,500 & 22 \\
\hline & Recovering from typhoid fever & $\mathbf{M}$ & 16 & 1.78 & 1,500 & 30 \\
\hline & Healing chest wound & $\mathbf{M}$ & 37 & 1.90 & 1,500 & 27 \\
\hline & Mean & & 31 & 1.78 & 1,118 & 21 \\
\hline
\end{tabular}

${ }^{*} \mathrm{BSA}=$ body surface area. 

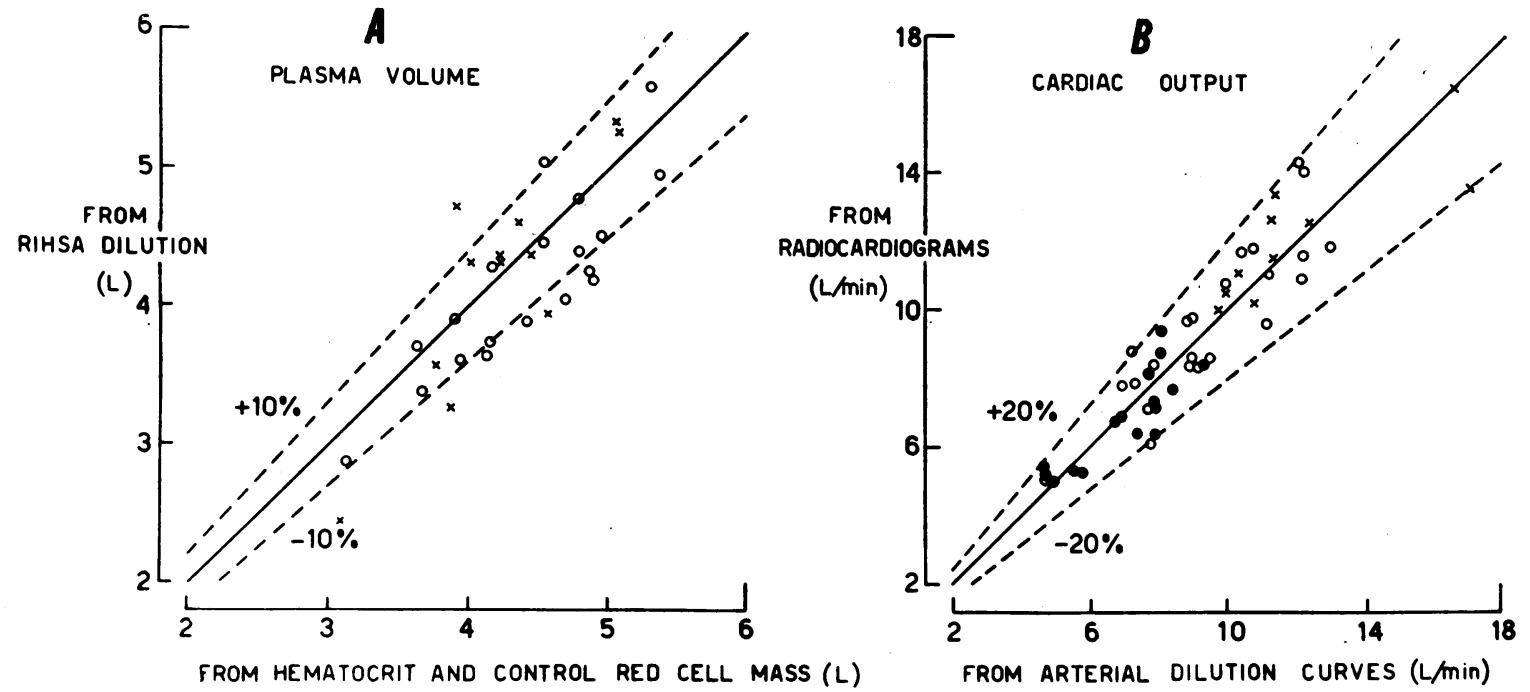

Fig. 1. A) CoMparison OF THE PLASMa VOLUME DETERMINED DiRECTLY FROM THE DILUTION OF RIHSA with THAT OBTAINED FROM THE HEMATOCRIT AND THE CONTROL RED CELL MASS. B) COMPARISON OF THE CARDIAC OUTPUT OBTAINED FROM THE RADIOCARDIOGRAMS WITH THAT CALCULATED FROM ARTERIAL OR LEFT VENTRICULAR RIHSA DILUTION CURVES. Open circles represent the values after dextran infusion; crosses indicate the determinations after atropine injection. In $\mathrm{B}$, solid circles stand for control values. RIHSA = radioiodinated human serum albumin.

topographic selectivity of counting efficiency while ensuring a statistically adequate counting rate. The center of the heart shadow, not including the vascular stem, was made to coincide under fluoroscopy with the center of a metal ring with a $5-\mathrm{cm}$ i. d. The collimator was then positioned over the area encircled by the ring, $1 \mathrm{~cm}$ above the skin of the subject. Impulses from the detector were counted by a digital integrator ${ }^{4}$ and recorded every 0.1 second. This instrument follows fast changes in counting rate without delay, thus eliminating the need to correct for the time constant distortion of ordinary rate meters. The injection of RIHSA was carried out by preloading the right atrial catheter with $0.5 \mathrm{ml}$ of solution and flushing it with saline. Both operations were performed with semiautomatic calibrated syringes. ${ }^{5}$ The calculations to obtain cardiac output from RCG were done in the usual way (21). Arterial and left ventricular dilution curves were obtained by drawing blood with the Teflon tube passing through a hole drilled across a $1.5-\times 1.5$-inch $\mathrm{NaI}(\mathrm{T} 1)$ shielded cylindrical crystal. ${ }^{3}$ The dilution curve was recorded with the aid of a commercial rate meter with a time constant of 0.5 second. When sampling from a peripheral artery, the tube, with $1.9-\mathrm{mm}$ i. d., was about $30 \mathrm{~cm}$ long and was connected to an indwelling Cournand needle. When sampling from the left ventricle, the tube was about $110 \mathrm{~cm}$ long and had two lateral holes within $2 \mathrm{~cm}$ of its distal opening. Sampling was done manually with a $50-\mathrm{ml}$ syringe and timed with a metronome at a rate of about $2 \mathrm{ml}$ per second. In order to

4 Built by P. Franzini, Istituto di Fisica Sperimentale, Università di Pisa, Pisa, Italy.

5 Becton, Dickinson \& Co., Rutherford, N. J. calculate cardiac output, we calibrated each curve individually with the pool sample technic (24).

Pulmonary and central blood volume determinations. Pulmonary blood volume (PBV) was calculated as the product of the stroke volume (SV) and the pulmonary mean transit time in heart cycles obtained from RCG, as previously reported (23). The average percentile variation of $P B V$ about the mean value of duplicate determinations was 2.7, ranging from 0.2 to 7.7, and the anatomic limits are defined by the pulmonary valve and the left atrial blood, which, in normal subjects, is included in PBV for a small fraction (23). Central blood volume $(\mathrm{CBV})$ was obtained as the product of $\mathrm{SV}$ times the central mean transit time in heart cycles. This transit time was calculated with the classical Stewart-Hamilton formula from left ventricular dilution curves corrected for catheter and rate meter distortions. This correction was accomplished by numerical deconvolution (25) of the left ventricular curves with the catheter transfer function. This function was determined separately by drawing a radioactive solution from a flask with the same catheter and instrumental setup of the in vivo studies. The anatomic limits of $\mathrm{CBV}$ are represented by the right atrium and the left ventricle, i. e., the two heart chambers into and from which RIHSA was injected and sampled, respectively.

Pressure measurement. Pressures were measured by means of two P23AA Statham strain gauges ${ }^{6}$ with the zero reference level set at $5 \mathrm{~cm}$ below the sternal angle. Tracings, including an electrocardiogram lead, were registered on a DR8 recorder. ${ }^{7}$ Mean pressures were

${ }^{6}$ Statham Instruments, Inc., Hato Rey, Puerto Rico.

7 Electronics for Medicine, Inc., White Plains, N. Y. 


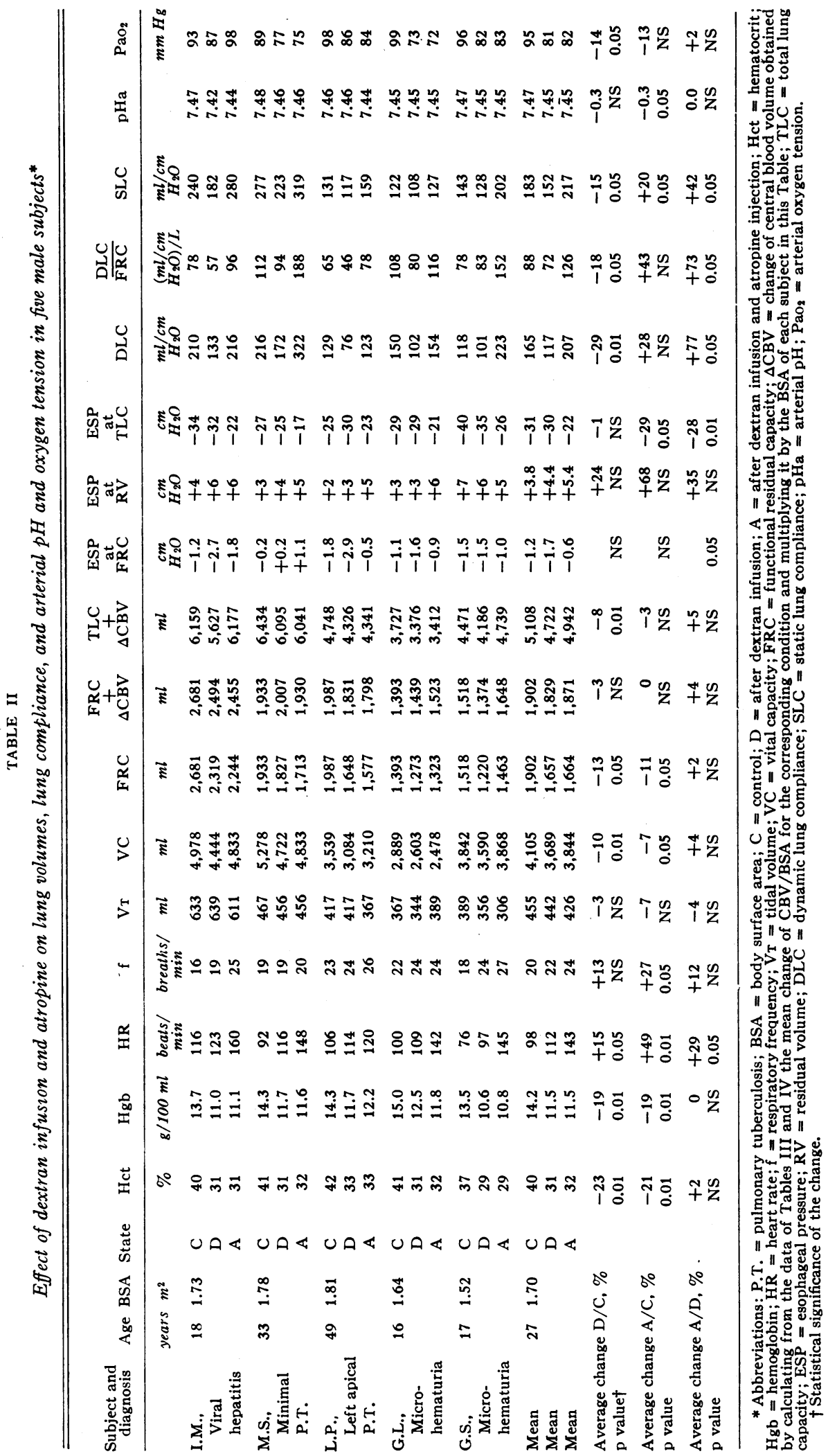


calculated by planimetry over at least three respiratory cycles. The numerous pressure readings obtained were then interpolated, and the values used for calculations and correlations were read at the time of the RCG. Mean pulmonary intravascular pressure (MPIP) was computed by averaging mean pulmonary arterial and wedge pressures (MPAP and MPWP, respectively).

Calculations of pulmonary vascular distensibility. It was shown by Engelberg and DuBois, in the rabbit, that the various segments of the pulmonary vasculature have a different distensibility (26). If a uniform variation of MPIP in all the pulmonary vessels and no change of transpulmonary pressure are assumed, the pulmonary vascular distensibility (PVD), representing the sum of the distensibility of all the vascular segments, may be calculated as $\mathrm{PVD}=\left(\Delta \mathrm{PBV} / \mathrm{m}^{2}\right) / \Delta \mathrm{MPIP}$, i. e., the change in volume of the bed divided by the change of mean intravascular pressure within the bed, both taken from the control level. Since the relationship between volume and transmural pressure in the pulmonary vasculature is not linear, in that PVD decreases with increasing volume (26-28), variations of PVD may, in general, be ascribed to variation of vascular tone only when PVD and volume vary in the same sense. Furthermore the influence of mechanical factors, such as interstitial perivascular edema, should be ruled out before invoking pulmonary vasomotricity.

The distensibility of the resistive vessels was assessed from the combined evaluation of MPWP and pulmonary vascular resistance (PVR), the latter calculated as $\mathrm{PVR}=(\mathrm{MPAP}-\mathrm{MPWP}) /\left(\dot{\mathrm{Q}} / \mathrm{m}^{2}\right)$, where the pressures are in millimeters $\mathrm{Hg}$ and the cardiac output $(\dot{Q})$ is in liters per minute. The limitations and the meaning of calculated PVR (29) will be considered subsequently.

Radiation dosimetry. About $80 \mu \mathrm{c}$ of RIHSA was injected for each curve. The maximal dose of ${ }^{1 s 1} \mathrm{I}$ given in the form of RIHSA to a patient was $350 \mu \mathrm{c}$. Since the preferential uptake of iodine by the thyroid was suppressed with Lugol's solution, this amount of ${ }^{181} \mathrm{I}$ will result in a maximal integral dose of radiation absorbed by the whole body of about $0.7 \mathrm{rad}$.

\section{Lung compliance}

Subjects. Five subjects were selected for this study. Their physical characteristics and diagnoses are listed in Table II.

Protocol. All subjects were studied in a supine and fasting condition. A latex balloon connected to a Teflon tube for measuring esophageal pressure (ESP) was introduced through the mouth and the balloon tip placed at a distance $40 \mathrm{~cm}$ from the teeth. At this depth, the balloon should be in the middle third of the esophagus, where the shape of lung volume-pressure curves was found to be only slightly affected at the lower lung volumes by changes in body posture, including the supine position (30). The Teflon tube was inserted through the mouthpiece, which connected the subject to a spirometer. A cannula was inserted into an arm vein for the infusion of dextran, and an indwelling arterial needle was placed in a brachial artery to draw blood samples. Each set of measurements comprised determination of hematocrit, hemoglobin concentration, arterial $\mathrm{pH}$ and oxygen tension, ventilation, vital and functional residual capacities, esophageal pressure, and dynamic and static lung compliances. Measurements were taken about 1 hour after the patients assumed the supine position, a few minutes after dextran infusion, and finally when the effect of atropine, as judged from the pulse rate, was evident.

Lung volume determinations. Lung volumes were recorded by means of a 9-L Knipping closed-circuit spirometer. Functional residual capacity (FRC) was measured by the closed-circuit helium technic.

Determination of dynamic and static lung compliances. The esophageal balloon had a length of $12 \mathrm{~cm}$ and a perimeter of $3 \mathrm{~cm}$. After a Valsalva maneuver, a very small amount of air, according to the specifications of Milic-Emili, Mead, Turner, and Glauser (31), was left in the balloon, which was then connected to one arm of a Sanborn differential transducer, model 270.8 The other arm of the transducer was connected to a side opening in the mouthpiece. Respiratory volumes were obtained by a potentiometer applied to the pulley of the spirometer bell. Transducer and potentiometer outputs were fed into the DR8 recorder. ${ }^{7}$ Compliances were measured after some full inspirations (32). Dynamic lung compliance (DLC) was obtained by determining the pressure difference between mouth and esophagus and the tidal volume excursion during quiet breathing over many respiratory cycles. Pressure and volume variations were taken between points of zero air flow. Static lung compliance (SLC) was measured in the following way: starting from the total lung capacity (TLC) level, the subjects expired to the residual volume (RV), and the expiration was periodically interrupted for 4- to 5-second periods by closing a valve in the mouthpiece. Thus, six to eight steps could be obtained on the pressure-volume curve during lung deflation. Static compliance values were obtained; they related the change in volume to the change in pressure observed moving from the 60 to the $40 \%$ level of vital capacity (VC). Over this range the pressure-volume curves were found to be practically rectilinear in every instance.

Determination of hemoglobin concentration and arterial $p H$ and oxygen tension. The hemoglobin was determined photometrically (33). The $\mathrm{pH}$ and the oxygen tension $\left(\mathrm{PO}_{2}\right)$ were measured with an electrode system. ${ }^{9}$

\section{Results}

\section{Pulmonary vascular distensibility}

In Figure 1, B, the cardiac output values calculated from RCG are plotted vs. those derived from RIHSA dilution curves. Since the points are

\footnotetext{
8 Sanborn Co., Waltham, Mass.

9 Model 113, Instrumentation Laboratory, Inc., Boston, Mass.
} 
uniformly distributed about the identity line, in each instance the average of the values obtained with the two methods was taken as cardiac output. The results obtained in the subjects who were given only dextran are reported in Table III (group 1), and those of the subjects who received dextran and atropine are presented in Table IV (group 2). The results obtained in Subject 195 are not reported in. Table IV because they were incomplete.

Dextran infusion. The hemodynamic changes observed after the infusion of dextran were uniform in the two groups when tested with the method of analysis of variance on randomized blocks (34). Only the modification of the ratio $\mathrm{PBV} / \mathrm{TBV}$ yields slightly different results in the two groups. Because of the uniformity of the results, the mean variations observed in the two groups after dextran were averaged, and the resulting figures are reported below.

The fall of the hematocrit was $22 \%$ and the rise of TBV $26 \%$, thus matching the amount of dextran solution infused. Heart rate increased by $16 \%$, cardiac output $36 \%$, and SV $18 \%$. Pulmonary mean transit time, measured in heart cycles, was unchanged; PBV rose by $16 \%$, the ratio $\mathrm{PBV} / \mathrm{TBV}$ decreased $7 \%$, and $\mathrm{CBV}$, in the six subjects of Tables III and IV in whom it was measured, increased, as did PBV, by $17 \%$. Mean pulmonary arterial pressure increased $102 \%$, MPWP 216\%, and left ventricular enddiastolic pressure (LVEDP), in the five subjects of Tables III and IV in whom it was measured, increased 234\%. Pressure gradient across the pulmonary circulation increased by $19 \%$, and MPIP rose $129 \%$. Calculated PVR de-

TABLE III

Effect of dextran infusion on pulmonary vascular distensibility in eight subjects*

\begin{tabular}{|c|c|c|c|c|c|c|c|c|c|c|c|c|c|c|}
\hline Subject & State & $\begin{array}{l}\text { Time } \\
\text { after } \\
\text { infu- } \\
\text { sion }\end{array}$ & Het & HR & $\dot{\mathbf{Q}}$ & PMTT & PBV & $\frac{P B V}{T B V}$ & CBV & MPAP & MPWP & LVEDP & PVD & PVR \\
\hline & & $\min$ & $\%$ & $\begin{array}{l}\text { beats/ } \\
\text { min }\end{array}$ & $L / \min$ & $\begin{array}{l}\text { heart } \\
\text { cycles }\end{array}$ & $m l$ & $\%$ & $m l$ & $m m \mathrm{Hg}$ & $m m H g$ & $m m \boldsymbol{H g}$ & 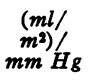 & $\underset{(L / m i n /}{\operatorname{mm}} \underset{\left.m^{2}\right)}{H g /}$ \\
\hline \multirow[t]{2}{*}{154} & C & & 43 & 82 & 7.92 & 6.2 & 601 & 12.1 & & 11 & 5 & & & 1.4 \\
\hline & $\mathrm{D}$ & 30 & 36 & 94 & 13.17 & 5.5 & 766 & 12.8 & & 22 & 14 & & 9.2 & 1.1 \\
\hline \multirow[t]{2}{*}{157} & C & & 43 & 77 & 7.55 & 7.2 & 704 & 12.2 & & 10 & 6 & & & 0.9 \\
\hline & D. & 30 & 34 & 88 & 10.38 & 7.1 & 831 & 11.7 & & 15 & 13 & & 12.2 & 0.3 \\
\hline \multirow[t]{2}{*}{158} & C & & 41 & 76 & 8.06 & 5.7 & 605 & 10.1 & & 14 & 9 & & & 1.1 \\
\hline & D & 32 & 34 & 78 & 9.24 & 5.4 & 632 & 8.9 & & 23 & 18 & & 1.7 & 0.9 \\
\hline \multirow[t]{2}{*}{159} & C & & 42 & 59 & 8.39 & 4.7 & 671 & 11.4 & & 15 & 10 & & & 1.2 \\
\hline & D & 48 & 35 & 97 & 11.28 & 6.4 & 743 & 10.9 & & 27 & 19 & & 3.5 & 1.4 \\
\hline \multirow[t]{2}{*}{173} & C & & 44 & 71 & 8.73 & 5.6 & 687 & 13.1 & & 13 & 6 & & & 1.5 \\
\hline & D & 24 & 37 & 94 & 13.13 & 5.9 & 826 & 13.3 & & 21 & 15 & & 8.4 & 0.9 \\
\hline \multirow[t]{4}{*}{185} & C & & 47 & 83 & 7.12 & 6.9 & 593 & 12.8 & 1,085 & 10 & 2 & 4 & & 2.0 \\
\hline & D & 6 & 37 & 82 & 8.68 & 6.6 & 708 & 12.2 & 1,310 & 22 & 14 & 15 & 5.6 & 1.6 \\
\hline & & 59 & 38 & 86 & 9.02 & 6.6 & 691 & 12.5 & 1,133 & 20 & 11 & 13 & 6.1 & 1.6 \\
\hline & & 100 & 38 & 86 & 9.39 & 6.4 & 705 & 12.9 & 1,153 & 19. & 9 & 11 & 8.0 & 1.7 \\
\hline \multirow[t]{4}{*}{187} & C & & 42 & 103 & 8.88 & 5.6 & 484 & 9.9 & 1,077 & 10 & 5 & 5 & & 1.0 \\
\hline & D & 8 & 29 & 113 & 11.52 & 5.5 & 562 & 8.1 & 1,198 & 32 & 23 & 24 & 2.3 & 1.3 \\
\hline & & 54 & 29 & 109 & 10.35 & 5.7 & 543 & 8.0 & 1,123 & 25 & 16 & 17 & 2.7 & 1.4 \\
\hline & & 92 & 30 & 105 & 11.07 & 5.4 & 568 & 8.5 & 1,067 & 24 & 14 & 15 & 4.3 & 1.4 \\
\hline \multirow[t]{3}{*}{207} & C & & 46 & 71 & 7.47 & 5.2 & 544 & 9.0 & 1,138 & 11 & 4 & 6 & & 1.8 \\
\hline & D & 5 & 35 & 95 & 12.41 & 5.2 & 683 & 8.7 & 1,412 & 26 & 15 & 21 & 5.7 & 1.6 \\
\hline & & 52 & 37 & 95 & 11.90 & 5.0 & 624 & 8.5 & 1,387 & 20 & 10 & 14 & 5.8 & 1.5 \\
\hline Mean & C & & 44 & 78 & 8.01 & 5.9 & 611 & 11.3 & 1,100 & 12 & 6 & 5 & & 1.4 \\
\hline Mean & D & 23 & 35 & 93 & 11.23 & 6.0 & 719 & 10.8 & 1,307 & 24 & 17 & 20 & 6.1 & 1.2 \\
\hline \multicolumn{2}{|c|}{$\begin{array}{l}\text { Average change } \\
\text { p valuet }\end{array}$} & e D/C, \% & $\begin{array}{l}-20 \\
0.01\end{array}$ & $\begin{array}{l}+21 \\
0.05\end{array}$ & $\begin{array}{l}+40 \\
0.01\end{array}$ & $\begin{array}{l}+2 \\
\text { NS }\end{array}$ & $\begin{array}{l}+18 \\
0.01\end{array}$ & $\begin{array}{l}-5 \\
\text { NS }\end{array}$ & +19 & $\begin{array}{c}+104 \\
0.01\end{array}$ & $\begin{array}{l}+234 \\
0.01\end{array}$ & +302 & & $\begin{array}{l}-16 \\
\text { NS }\end{array}$ \\
\hline
\end{tabular}

* Abbreviations: $\dot{Q}=$ cardiac output; PMTT = pulmonary mean transit time; $P B V=$ pulmonary blood volume; TBV $=$ total blood volume MPAP = mean pulmonary arterial pressure; MPWP = mean pulmonary wedge pressure; LVEDP $=$ left ventricular end-diastolic pressure; $\mathbf{P V D}=$ pulmonary vascular distensibility; $\mathbf{P V R}=$ pulmonary vascular resistance. t Statistical significance of the change. 
clined $12 \%$. Pulmonary vascular distensibility, measured after the infusion, was $5 \mathrm{ml}$ per $\mathrm{m}^{2}$ per $\mathrm{mm} \mathrm{Hg}$.

Atropine injection. The hemodynamic changes observed in the subjects who received atropine after dextran infusion were fairly uniform (Table IV).

The hematocrit was still $21 \%$ lower and TBV $22 \%$ larger than the respective control values, both variations being slightly reduced compared with the changes observed immediately after dextran. Heart rate increased $59 \%$ and cardiac output $101 \%$, the values of both parameters being significantly higher than after dextran infusion. Stroke volume rose $26 \%$ in respect to the control, but only $8 \%$ relative to the postinfusion value. Pulmonary mean transit time was insignificantly prolonged both with regard to control $(+4 \%)$ and postdextran $(+6 \%)$ determinations. The PBV rose $31 \%$ above the control and $14 \%$ above the postinfusion figures. The ratio $\mathrm{PBV} / \mathrm{TBV}$ presented an insignificant rise $(+8 \%)$ compared to the control value, but increased significantly $(+18 \%)$ above the postdextran level. The CBV was $21 \%$ larger than the control value, being only slightly augmented $(+5 \%)$ from the postinfusion level. Pulmonary arterial and wedge pressures and MPIP were still significantly higher by $50 \%$, $84 \%$, and $54 \%$, respectively, than the control measurements, all being significantly reduced with regard to the postdextran levels by $22 \%, 33 \%$, and $26 \%$, respectively. Pulmonary pressure gradient showed insignificant increments, both with respect to control and postinfusion values, whereas PVR fell significantly below control $(-38 \%)$ and postdextran $(-32 \%)$ levels. The PVD showed a fivefold increase above the postinfusion value, from 4.5 to $22.9 \mathrm{ml}$ per m² $\mathrm{mm} \mathrm{Hg}$.

When a second set of measurements was taken some time after atropine injection, the results were not uniform, which indicates that they apparently depend on the time that has elapsed after administration of the drug (Table IV).

\section{Lung compliance}

The results obtained in the five subjects studied are reported in Table II. The changes observed after dextran infusion and atropine in- jection were tested with the method of analysis of variance on randomized blocks (34).

Dextran infusion. After the infusion of dextran the hematocrit value, corrected for trapped plasma, showed a reduction slightly but definitely greater than the hemoglobin concentration, in each subject. On the average, the former fell $23 \%$ and the latter $19 \%$. The same observation was made in two subjects of the previous groups in whom the hemoglobin concentration was determined. The increase of heart rate $(+15 \%)$ was similar to that found during the study of PVD. The frequency of respiration, the tidal volume, and the total ventilation did not show significant changes with respect to the control level. However, their variations, which appear small but rather consistent, might become significant in a larger population sample. Vital capacity decreased significantly $(-10 \%)$ as did TLC, even after correction for the estimated increase of CBV (-8\%). The ESP at FRC went from the control level of -1.2 to $-1.7 \mathrm{~cm} \mathrm{H}_{2} \mathrm{O}$. This variation was not significant. The variations of ESP at RV and TLC were also not statistically significant. Dynamic and static lung compliances were reduced by 29 and $15 \%$, respectively, after dextran infusion. The ratio DLC/FRC also appeared to be significantly reduced $(-18 \%)$. The arterial $\mathrm{pH}$ decreased from 7.47 to 7.45 , and arterial $\mathrm{Po}_{2}$ was. significantly lowered (-14\%).

Atropine injection. After administration of atropine, the frequency of respiration increased $27 \%$ with regard to control and $12 \%$ in respect to postdextran levels. The tidal volume values were somewhat lower than those observed in the other two conditions. Vital capacity was $7 \%$ below the control measurement but $4 \%$ above the postdextran level. After correction for the estimated increase of CBV, TLC was not significantly reduced below control $(-3 \%)$ and not significantly increased above postdextran values $(+5 \%)$. The ESP at FRC was, on the average, $-0.6 \mathrm{~cm} \mathrm{H}_{2} \mathrm{O}$, a value somewhat less negative than those observed during the control and the postinfusion periods. The ESP at RV was, respectively, 1.6 and $1.0 \mathrm{~cm} \mathrm{H}_{2} \mathrm{O}$, more positive than the control and postdextran determinations, whereas at TLC it was, respectively, 9.2 and 8.4 $\mathrm{cm} \mathrm{H}_{2} \mathrm{O}$, less negative. These last two differences were statistically significant. The DLC and 
the ratio DLC/FRC were increased, respectively, by 28 and $43 \%$ above the control and 77 and $73 \%$ above the postinfusion levels. Because of differences in the intensity of the individual response and the smallness of the population sample, variation with respect to control value failed to attain statistical significance. The SLC after atropine rose significantly with respect to both control $(+20 \%)$ and postdextran $(+42 \%)$ measurements. The arterial $\mathrm{pH}$ was somewhat reduced compared with the control determination. The arterial $\mathrm{Po}_{2}$ remained, except for one subject, at the postinfusion level.

\section{Discussion}

\section{Pulmonary vascular distensibility}

Comparison with previous results. The observed variations of the hematocrit value and of TBV and their duration after dextran infusion are in agreement with preceding reports (35-38). Some conflict exists in the literature on the effect of induced hypervolemia on cardiac output. Infusions of albumin and saline produced inconstant increases of cardiac output $(39,40)$, whereas blood infusion did not affect it $(41,42)$. The increase in cardiac output after infusions has been attributed to the anemia produced thereby (41), but this interpretation has been questioned (43). Probably, the variations of the total effective blood volume (44) and of the extracellular volume (43) may also influence the cardiac output. As to the effect of dextran infusion, previous findings show a variable increase of cardiac output probably depending on the rate of infusion and the amount given (35-37) ; our results are in general agreement with these reports. The increase of cardiac output resulted from a rise of both stroke volume and heart rate; this is also in agreement with previous observations (37).

Few data are available concerning the effects of infusions on central blood volumes. The present study shows a moderate increment of pulmonary blood volume and central blood volume and a small decrement of the ratios $\mathrm{PBV} / \mathrm{TBV}$ and $\mathrm{CBV} /$ TBV. An increase of the blood volume in the lungs, left heart, aorta, and certain large arteries was also found in humans by Witham, Fleming, and Bloom, when they infused dextran (35). Increase of the blood volume from inferior vena cava to left atrium in man has recently been reported by De Freitas. and associates after infusion of 1,000 $\mathrm{ml}$ of polyvinylpyrrolidone (44). These authors, however, found that most of the increase occurs upstream to the pulmonic valve, whereas PBV, as determined from the difference in mean transit times of the left atrial and pulmonary arterial dilution curves, increases only $3 \%$. This negligible change is somewhat at variance with our observation of $16 \%$ increase of PBV after the infusion of $1,100 \mathrm{ml}$ of dextran. It appears likely that this difference in the behavior of PBV is real and depends on the duration and modality of the infusion, which differ in the two series. This interpretation is in keeping with the behavior of the pulmonary vascular resistances, which tend to rise $+17 \%$ and to fall $-12 \%$ in the subjects of De Freitas and associates (44) and in our subjects (Figure 2), respectively. Similar considerations seem also to apply to the findings of Varnauskas, Korsgren, Houk, and Prérovský (46), who recently reported no systematic increase of $\mathrm{PBV}$ with some elevation of PVR after the infusion of $500 \mathrm{ml}$ of rheomacrodex given at a rate of 10 to 20 $\mathrm{ml}$ per minute, which is much lower than our mean infusion rate for macrodex of $54 \mathrm{ml}$ per minute.

The elevation of mean pulmonary arterial and wedge pressures observed in our subjects is comparable in degree and duration to that reported by Witham and co-workers (35) and Fleming and Bloom (36). Also, the data of Schnabel, Eliasch, Thomasson, and Werkö concerning the pulmonary arterial pressure measured during and a few minutes after the infusion compare well with our findings (37). No comparison with other reports can be made for left ventricular end-diastolic pressure that showed practically the same behavior of MPWP. In the present study the rise in pressure is rather uniform throughout the central circulation, with an increase of $12 \mathrm{~mm} \mathrm{Hg}$ in MPAP and $11 \mathrm{~mm} \mathrm{Hg}$ in MPWP. De Freitas and associates report, in their previously mentioned study, an elevation of $10.3 \mathrm{~mm} \mathrm{Hg}$ in MPAP and $6.4 \mathrm{~mm} \mathrm{Hg}$ in mean left atrial pressure (MLAP). This significantly larger increase of MPAP with respect to MLAP may be due to the shorter time from the end of the infusion to the measurement of the pressure, since, in our studies, MPAP often appears more elevated than MPWP just after the infusion. 

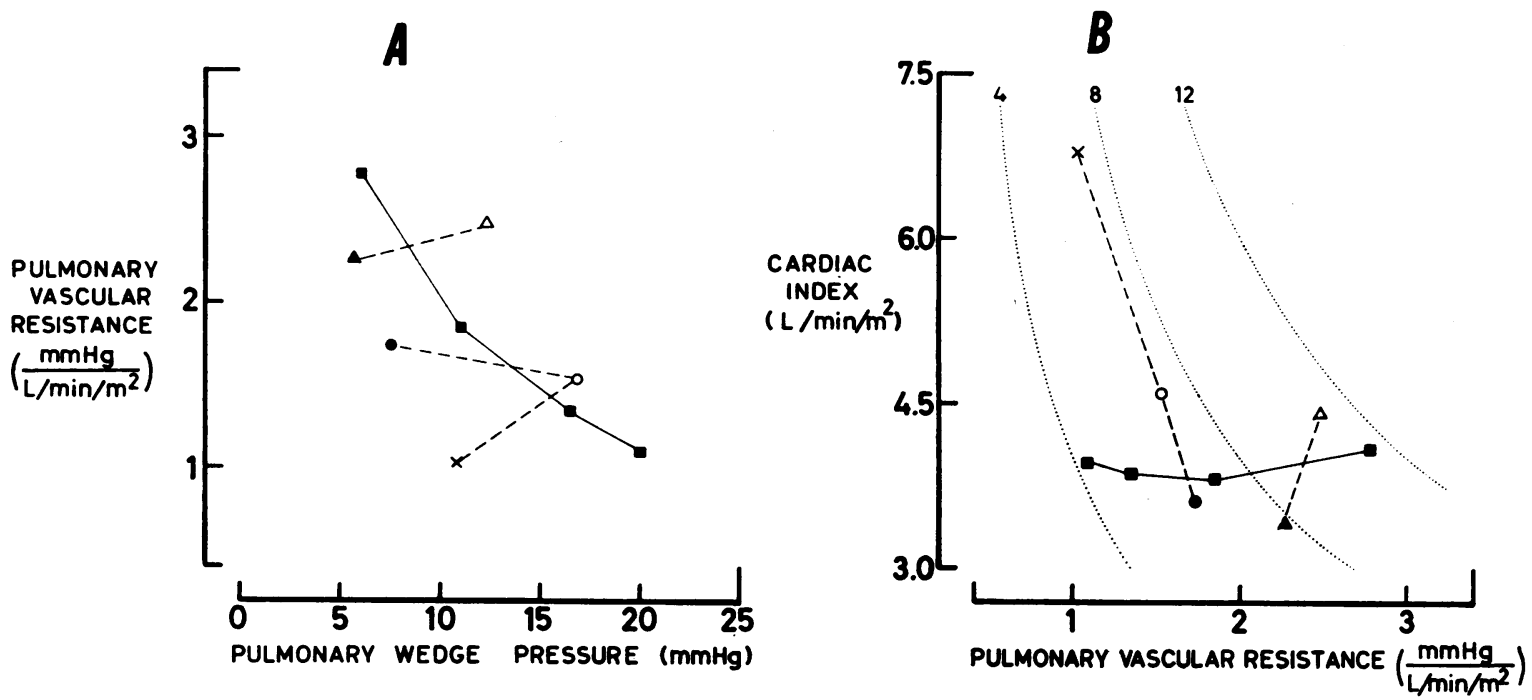

Fig. 2. A) The Relationship between pUlmonary vascular resistance (PVR) (ORdinate) ANd MEAN PULMONARY WEDGE PRESSURE (MPWP) (ABSCISSA) IN THE CONTROL STATE (SOLID CIRCLE), AFTER DEXTRAN INFUSION (OPEN CIRCLE), AND AFTER THE POSTINFUSION ATROPINE INJECTION (CROSS). B) RELATIVE CONTRIBUTION OF CHANGES IN CARDIAC INDEX AND PULMONARY PRESSURE GRADIENT (ISOPLETHS IN MILLIMETERS Hg) TO CHANGES IN PVR UNDER THE SAME Conditions AS A. The values are the averages of group 2 (Table IV). The same relationship in the control state (solid triangle) and after polyvinylpyrrolidone infusion (open triangle) was derived from the averaged data of De Freitas and associates (44). Solid squares= averages of determinations in anesthetized dogs at increasing levels of mean pulmonary venous pressure (45). The negative esophageal pressure at functional residual capacity (FRC) (Table II) was added to our MPWP and to the mean left atrial pressure calculated by De Freitas to have a reference zero at a level comparable to the intrathoracic pressure used in the dogs.

The present study shows a striking increase of cardiac output when atropine is administered after dextran infusion in recumbent subjects. Under these circumstances, SV tends to rise, and the sharp increase of heart rate is responsible for most of the elevation of cardiac output. Weissler, Leonard, and Warren studied the effect of atropine on cardiac output and SV by tilting subjects, employing antigravity suits, and placing pneumatic cuffs on three extremities, and they concluded that the effect depended on the size of the central venous reservoir (11). Berry, Thompson, Miller, and McIntosh obtained some elevation of SV and a striking increase of cardiac output with a rapid intravenous infusion of albumin in subjects that had been given atropine and suggested that the increasing venous return was responsible for the modification of the atropine action (13). All these findings seem in keeping with our results.

No data are available concerning the effect of atropine on PBV under conditions of increased venous return.

In our study atropine seemed to hasten the de- cline of all the central pressures. This finding appears consistent with the observations of several authors who found a reduction of central venous pressure after atropine in supine subjects (10-15). In particular, it is in keeping with the observations reported by Daly, Ross, and Behnke that the rise of mean right atrial and pulmonary arterial pressures accompanying antigravity suit inflation was considerably lower after atropine administration (15).

Changes of pulmonary vascular distensibility. The use of mean pulmonary intravascular pressure in the volume-pressure relationship of the entire vascular bed and for the calculation of over-all pulmonary vascular distensibility appears justified in the present study for the following reasons: 1) After dextran infusion and atropine injection, MPAP, MPWP, and LVEDP exhibit almost identical variations, so that any one could be used to evaluate the distensibility of the pulmonary vasculature; MPIP was chosen as a better approximation of the intravascular pressure existing throughout the lung circulation. 2) Changes in 
the fraction of total PBV in the different segments of the pulmonary vasculature, which are discussed below, appear inadequate to produce pressure variations within the lung circulation of the order of those observed at its extremes, i.e., changes of the pressure profile should be insignificant compared with variations of MPIP. 3) The minimal differences in esophageal pressure during the control period, after dextran infusion, and after atropine injection indicate that variations of MPIP may be considered a faithful expression of changes in transmural pressure of the lung vessels.

The $129 \%$ rise of MPIP as compared with the $16 \%$ increase of $\mathrm{PBV}$ observed in this study after dextran infusion does not support the belief that the pulmonary vascular bed can passively accommodate large quantities of blood by acting as a reservoir for acute changes and redistributions of TBV (47). Even the widely held concept that the pulmonary vascular bed is a highly distensible system $(48,49)$ does not seem consistent with these findings and probably requires limitation under several circumstances. The present data are substantially in agreement with the observations of Doyle, Lee, and Kelly (50), De Freitas and associates (44), and Varnauskas and co-workers (46), who infused saline, polyvinylpyrrolidone, and rheomacrodex solutions, respectively, measured central $(50)$ and pulmonary $(44,46)$ blood volumes, and concluded that the pulmonary circulation behaves, under these circumstances, as a bed of low distensibility. However, the appreciable rise of PBV observed in this study, in comparison with the lack of a significant rise reported by the latter two groups $(44,46)$, suggests the possibility that the rate and the amount of the infusion overcome, to some extent, the mechanism that prevents any increase of PBV during acute hypervolemia.

The influence of mechanical factors such as interstitial perivascular edema should be discounted, since the hemodynamic situation is quite different from that under which perivascular edema is known to occur (51), and the levels of the left atrial and plasma colloid osmotic pressures, as discussed below, should not allow the increase of interstitial fluid in the lung $(52,53)$.

Passive mechanical properties of the lung vessels and surrounding tissues do not seem to ac- count by themselves for the observed low PVD. In fact, the presence of an active mechanism opposing the distention of the pulmonary vessels in the face of an increasing transmural pressure is suggested by the subsequent expansion of $\mathrm{PBV}$ accompanying a decline of MPIP after atropine injection.

Furthermore, Figure 3 suggests that, after dextran infusion, the value of PVD is lower than in the control and postatropine periods. The experimental points after dextran infusion deviate from the pressure-volume relationship observed in the other two conditions, since PBV per meter squared tends to be smaller at higher pressures.

After atropine injection the higher values of PBV and the fivefold elevation of PVD, with respect to the postdextran levels, indicate a striking increase of compliance of the bed, since, for a given pressure-volume curve, the value of calculated PVD is lower at larger PBV. Such a variation of distensibility does not seem to occur spontaneously after dextran infusion. Only exceedingly small increments of PVD occur up to 100 minutes after the infusion, whereas atropine injection promptly enhances PVD.

The variations that occur in the pulmonary circulation spontaneously 1 to 2 hours after the infusion of dextran mainly concern the pressures, which present small but definite decrements, whereas PBV hardly shows any decrease from the postinfusion values. Stress relaxation or hysteresis, as an expression of passive yielding in time of the vascular walls to pressure elevation, cannot be ruled out in accounting for this fall in pressure, although it would then occur long after 1 minute, during which it could be detected by the methods of Sarnoff and Berglund on the isolated dog lung (27), Sarnoff, Berglund, and Sarnoff on the lungs of anesthetized open-chest dogs (28), and Frank, Radford, and Whittenberger on excised lungs of cats (56). The decline of pressure in our studies appears to follow a time course similar to that reported for MPAP by Sancetta and Rakita during prolonged steady state exercise (57). The decrease of MPAP observed by Widimsky, Berglund, and Malmberg during repeated exercise seems also to have a time constant of the same order (58). The observed tendency to moderate pressure decrease after infusion could also be ascribed to a small active increase of PVD. 

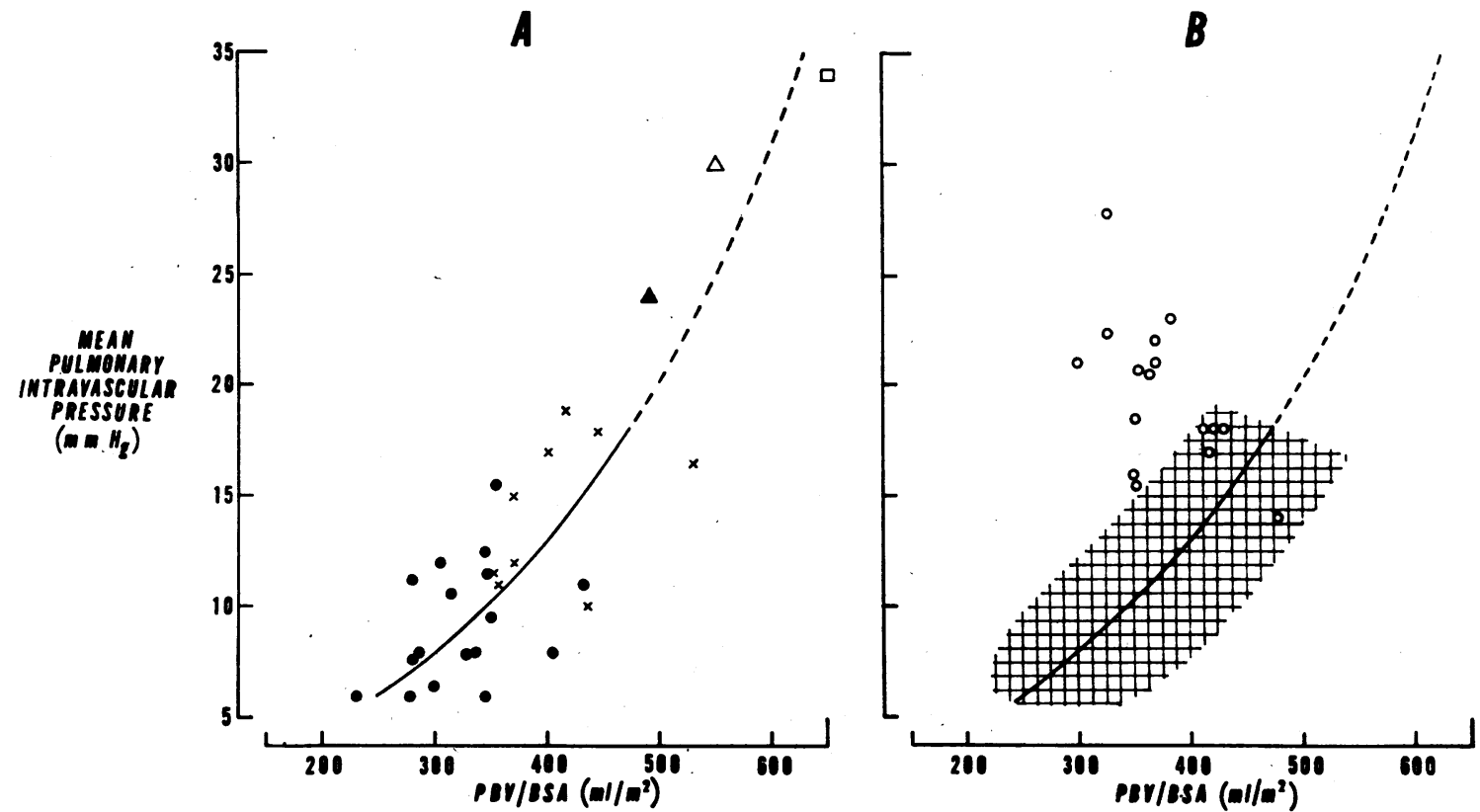

Fig. 3. A) The PRESSURE-volume Relationship in the pUlmonary CirCulation in the control State (SOLID CIRCLES) AND AFTER THE POSTINFUSION ATROPINE INJECTION (CROSSES). B) THE PRESSURE-VOLUME RELATIONSHIP IN THE PULMONARY CIRCULATION AFTER DEXTRAN INFUSION (OPEN CIRCLES). In A, a freehand curve (solid line) was fitted to the data (54), which apparently lie around the same function. The extrapolation of this curvilinear relation (dashed line) appears also to fit determinations made in anesthetized dogs: solid triangle $=6$ dogs (55); open triangle $=11$ dogs $(53) ;$ square $=1 \mathrm{dog}(28)$. The plotted value of pulmonary blood volume (PBV) of these observations in dogs was computed from the percentage rise of the $\mathrm{PBV}$ in the dogs after normalizing the control value to our controT PBV. We obtained the plotted value of the pressure in the dogs by adding the. rise above the control level of the mean left atrial pressure in the dogs to our control mean pulmonary intravascular pressure (MPIP). $\mathrm{BSA}=$ body surface area. In $\mathrm{B}$, the crosshatched area includes all the control and postatropine determinations. The freehand curve of $\mathrm{A}$ is drawn as reference.

As previously mentioned, PVD represents, for a uniform pressure change, the sum of the distensibility of all the different segments of the pulmonary circulation. In an attempt to gain some information on the distribution of the pressurevolume relationship in the pulmonary vasculature, pulmonary arterial compliance was calculated according to the method proposed by Engelberg and DuBois (26). Unfortunately, the reproducibility of the results was so poor that they could not be used.

Relatively more dependable information on the pressure-volume characteristics of different parts of the pulmonary vascular bed was derived from the combined evaluation of PVR and MPWP. After dextran infusion, PVR showed, on the average, a $12 \%$ decrease, which was not statistically significant. Even if this change were significant, it would imply an increase of volume of the resistance vessels smaller than the average PBV rise.
This conclusion is based on the use of Poiseuille's law and appears justified for the following reasons: 1) there is no reason to believe that the length of the vessels is increased, since the lung volumes are unchanged or reduced; and 2) the reduction of the coefficient of viscosity of the blood after dextran infusion (59) may lead, per se, to an increase of the calculated cross section of the resistance vessels. It cannot be decided whether the small volume increment of the resistance vessels is due to an increase in the diameters of patent vessels or in the number of parallel vessels being perfused. If the latter mechanism prevailed, the distensibility of the resistance vessels under these circumstances would be even lower than that estimated from their small volume increment.

In relation to the passive mechanisms that might conceivably affect PVR after dextran infusion, it should be remarked that: 1) The increase in pulmonary blood flow should lead to a reduction of 
PVR. 2) The alveolar pressures are certainly well below the level of MPWP, and no change of alveolar surface tensions should develop after dextran infusion unless alveolar edema is occurring (60). 3) The conditions for the formation of pericapillary edema do not exist $(52,53)$. 4) The change of ESP is negligible compared to that of MPWP (Figure 4). 5) Reduction or obstruction of the vascular lumen by cellular aggregates or dextran adsorbed onto the vessel walls should be discounted, since it does not seem compatible with the sudden change of PVR observed after atropine injection. Therefore, the insignificant decline of PVR in the presence of an elevation of MPWP of $10 \mathrm{~mm} \mathrm{Hg}$ strongly suggests the existence of vasomotor activity in the resistance vessels, since the results obtained by Haddy and Campbell on anesthetized dogs indicate that such an increase of

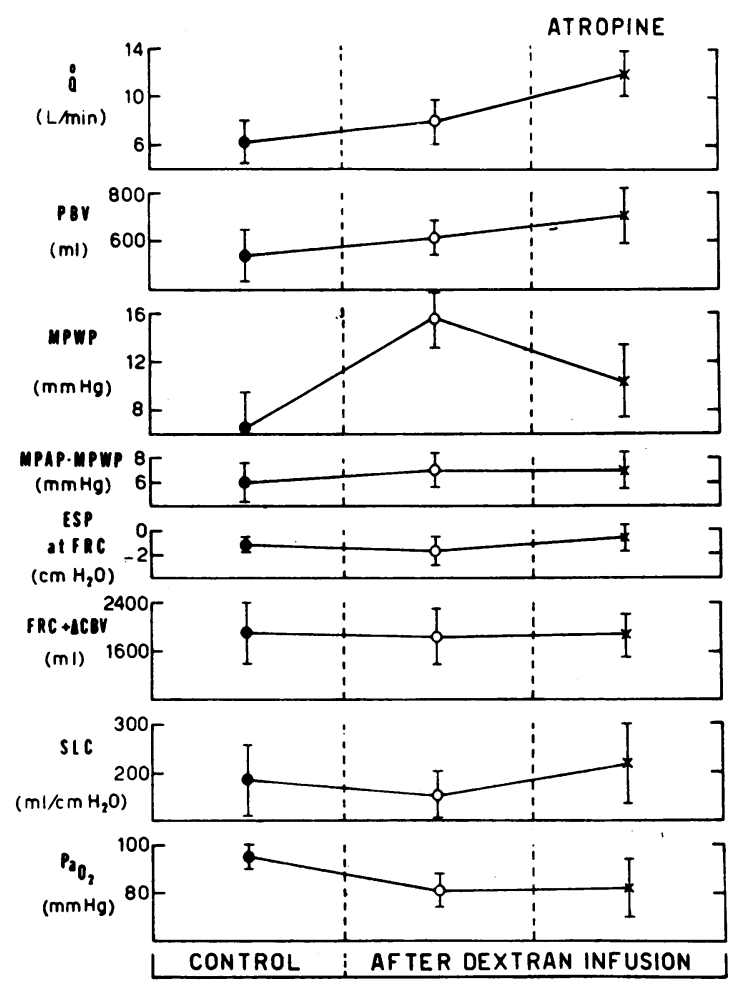

Fig. 4. COMBINED EFFECTS ON PULMONARY HEMOdYNAMICS AND LUNG MECHANICS OF DEXTRAN INFUSION AND SUBSEQUENT ATROPINE INJECTION. The data are group averages from Tables II and IV, and the vertical bars represent $1 \mathrm{SD}$. $\dot{Q}=$ cardiac output; MPAP - MPWP $=$ pulmonary pressure gradient $; \mathrm{ESP}=$ esophageal pressure; $F R C+\triangle C B V=$ functional residual capacity plus change of central blood volume; SLC = static lung compliance; $\mathrm{PaO}_{2}=$ arterial oxygen tension. distending pressure practically halves the value of PVR (45) (Figure 2). Similar observations have also been made in isolated lungs of cats (61) and repeated on anesthetized dogs $(48,62)$.

The administration of atropine appears to diminish the vasomotor tone, since it causes a significant drop of both PVR $(-32 \%)$ and MPWP $(-33 \%)$. This fall of PVR with respect to the postdextran level probably implies an increment in volume of the resistance vessels somewhat higher than that of total PBV. The difference between control and postatropine PVR ( $-38 \%)$ is also statistically significant, but it cannot be taken as an indication of a decline of control vasomotor tone, since it is associated with a rise of MPWP $(+84 \%)$.

It is generally agreed that the size of the pulmonary capillary bed, as measured with the technic of Roughton and Forster (63), is directly dependent on the level of the transmural pulmonary vascular pressure $(15,64,65)$. In particular, it has recently been reported that elevation of the transmural pressure by infusion of dextran and epinephrine to anesthetized dogs raises the pulmonary capillary blood volume (66). It seems reasonable to infer that the size of the pulmonary capillary bed and PVR may vary independently, since after dextran infusion and atropine injection, respectively, PVR hardly declined when MPWP rose $10 \mathrm{~mm} \mathrm{Hg}$ and fell markedly when MPWP decreased $5 \mathrm{~mm} \mathrm{Hg}$. This inference is in agreement with the conclusions, reached by Lawson, Duke, Hyde, and Forster for the isolated cat lung, that the vessels contributing the major vascular resistance in the lung are not necessarily important in regulating the capillary bed volume (64).

It thus appears that nonuniform variations of volume may occur in different parts of the pulmonary circulation.

\section{Total lung compliance}

Comparison with previous results and validity of $S L C$ and DLC. After dextran infusion, static lung compliance (SLC) showed a smaller reduction than dynamic lung compliance (DLC) with respect to the control values. The decrease of the latter was considerably smaller than that initially reported in seated men by gravity suit inflation (67). Bondurant, Mead, and Cook, in a re-evaluation of the effects of acute central con- 
gestion by gravity suit inflation, introduced some technical changes in the measure of ESP and obtained a reduction of DLC of the same order as that observed in the present study (68). However, these authors suggested that impingement on the esophagus by distended mediastinal structures, particularly the heart, caused falsely high end-expiratory pressures and falsely large respiratory fluctuations (68). It cannot be ruled out that an increase in heart volume may influence ESP in supine subjects. However, the increase of heart volume, as estimated from the difference between CBV and PBV, is rather small. Furthermore, ESP at residual volume, when the influence of distended mediastinal structures should be maximal, is only $0.6 \mathrm{~cm} \mathrm{H}_{2} \mathrm{O}$ higher than the control value, and ESP at functional residual capacity is $0.5 \mathrm{~cm} \mathrm{H}_{2} \mathrm{O}$ lower than the control level (Table II, Figure 4). These observations in our supine subjects indicate that ESP is probably not much disturbed under these circumstances by mediastinal influences. This conclusion is in agreement with the finding of Daly and Bondurant that acute central vascular engorgement during pressure suit inflation in seated men causes similar changes in esophageal and intrapleural pressures (69).

After atropine injection DLC rose more than SLC, both being significantly higher than in the control and postdextran periods. DLC in the control state, after dextran infusion, and after atropine administration was, respectively, 165, 117 , and $207 \mathrm{ml}$ per $\mathrm{cm} \mathrm{H}_{2} \mathrm{O}$. These figures obtained in supine subjects compare reasonably well with those of 193, 137, and $201 \mathrm{ml}$ per $\mathrm{cm} \mathrm{H}_{2} \mathrm{O}$ observed in seated subjects by Daly and co-workers in the control state, after gravity suit inflation, and after atropine injection and gravity suit inflation (15). The reduction of heart volume after atropine is rather small, as estimated from the difference between CBV and PBV, and it should not appreciably influence ESP, which, at any rate, is higher than in the control and postdextran periods by 1.6 and $1.0 \mathrm{~cm} \mathrm{H}_{2} \mathrm{O}$, respectively, at $\mathrm{RV}$, and by 0.6 and $1.1 \mathrm{~cm} \mathrm{H} \mathrm{H}_{2} \mathrm{O}$ at FRC (Table II, Figure 4). As pointed out by Daly and coworkers, on the basis of available information on the effects of atropine on alimentary smooth muscle, changes in esophageal compliance after atropine should decrease rather than increase the value of lung compliance as estimated with the technic of the esophageal balloon (15).

In any condition, SLC yields, on the average, higher values of lung compliance than DLC. The static measurements seem to provide a more dependable estimate of lung compliance. In fact, it has been shown that airway resistances increase after pulmonary vascular congestion $(15,53)$ and decrease after atropine (15). These changes of airway resistances may influence the distribution of the lung ventilation and, hence, affect DLC, but their effects should be minimized in the volumepressure curve obtained during stepwise expiration from TLC. The largest discrepancy between DLC and SLC occurs after dextran infusion, when uneven ventilation should be more marked.

Changes of total lung compliance. The reduction of lung compliance observed after dextran infusion may be ascribed to one or more of the following factors: $a$ ) surface phenomena occurring at the gas-liquid interface of the alveoli; $b$ ) pulmonary vascular congestion and elevation of pulmonary vascular pressures per se; and $c$ ) active stiffening of the bronchial, interstitial, and vascular tissues.

a) The contribution of the surface phenomena to total lung compliance depends on the surface tension and the geometry of the alveoli and bronchioles (70).

Surface tension does not seem altered after dextran infusion unless alveolar edema is developing (60). Edema formation is unlikely for the following reasons: 1) MLAP, as estimated from MPWP and LVEDP, was, in every instance, well below the critical level of $25 \mathrm{~mm} \mathrm{Hg}(52,53)$, and dextran infusion does not lower the plasma colloid osmotic pressure $(59) ; 2$ ) the reduction of lung compliance after dextran infusion was promptly reversed by the administration of atropine, whereas in the case of edema formation, the decrease in compliance was not reversed by lowering left atrial pressure (71).

The geometry of the terminal air spaces, excluding the alveolar edema, may be modified by the increase of $\mathrm{CBV}$ and the elevation of bronchial tone. Both these mechanisms increase the surface pressure of the air spaces by reducing the radius of terminal lung units, according to the Laplace relationship (71). The increase of CBV, however, corresponds to only $9 \%$ of control FRC, and 
since it can be shown that surface compliance is proportional to the cube root of volume (71), the resulting reduction of the lung air spaces should not cause a significant change of this compliance if uniform distribution of the increment of CBV is assumed. Bronchoconstriction, on the other hand, may be of mild degree, since wheezing was audible in our subjects only once and small increments of airway resistance were reported after pulmonary vascular engorgement $(15,53)$.

However, that increased CBV and bronchoconstriction are responsible for the closure of some ventilated units after dextran infusion cannot be excluded. Since total compliance is the sum of the compliance of all the parallel units, a reduction in the number of ventilated lung units would be associated with a reduction of the lung compliance. Consequently, in order to assess the distensibility of the lung units left open, it is necessary to take the ratio of compliance to ventilated lung volume and to consider whether any significant displacement of the volume-pressure curve of the functioning units has occurred. These limitations, however, apply only to the determination of DLC, which, although measured after deep inspirations, may still be influenced by the closure of some air spaces. At any rate, DLC/FRC was significantly reduced after dextran infusion, and the displacement of the lung volume-pressure curve is probably unimportant, since FRC plus change of CBV is very close to control FRC and ESP is only slightly more negative than control ESP (Table II). With distending pressures of sufficient magnitude, closed units are reopened, and the over-all distensibility of the lungs at highly negative ESP should not be influenced by the above mechanisms. Hence, increased $\mathrm{CBV}$ and bronchoconstriction should not account for the reduction of SLC observed after dextran infusion. This conclusion agrees with the fact that, after dextran infusion, vital capacity and total lung capacity plus change of $\mathrm{CBV}$ were reduced with respect to control value (Table II), whereas ESP $\left(-30 \mathrm{~cm} \mathrm{H}_{2} \mathrm{O}\right)$ was practically identical to control ESP $(-31$ $\mathrm{cm} \mathrm{H}_{2} \mathrm{O}$ ); it is supported by the observation of Yoshida that bronchoconstriction exerts only minimal effects on static pressure-volume curves obtained, as in this study, during deflation of a fully expanded lung (72).

b) The effect of pulmonary vascular congestion, per se, on lung mechanics has been investigated by several authors by elevating the pulmonary venous pressure in experimental conditions in which the influences of surface forces are minimized and active tissue changes should not take place. In the absence of edema formation, only small reductions of lung compliance were observed by Borst and co-workers on anesthetized open-chest dogs (73), Frank and co-workers (56) and Frank (74) on excised cats' lungs, and Cook and co-workers on anesthetized closed-chest dogs and isolated dog lungs (71). The reduction of lung compliance in our subjects after dextran infusion is smaller than that previously reported in man during comparable pulmonary vascular congestion but greater than that found in the quoted animal studies.

c) It may then be suggested by exclusion that elevation of the vascular and parenchymal smooth muscle tone contributes to the modest but definite increase in lung stiffness that follows acute expansion of TBV. This interpretation seems strengthened by the large changes of lung compliance observed in our subjects with the subsequent atropine injection.

After atropine, SLC rises even above the control level $(+20 \%)$ with an accompanying increase of $\mathrm{PBV}(+31 \%)$ and an elevation of MPWP $(+84 \%)$ with respect to the control values (Figure 4). This observation lends further support to the conclusion that pulmonary vascular engorgement and elevated pulmonary venous pressure are not per se important determinants of total lung compliance.

Owing to this scarce effect of pulmonary venous pressure on lung compliance, relaxation of smooth muscle tone appears to play the main role in the remarkable increase of SLC with respect to the postinfusion value $(+42 \%)$ after the intravenous injection of atropine. In fact, the observed fall of about $5 \mathrm{~mm} \mathrm{Hg}$ in venous pressure with respect to the postinfusion period cannot account for the rise of SLC.

\section{Conclusions}

As previously discussed, the conclusion that passive mechanical factors do not seem to account for the low PVD, for the constant PVR with elevated MPWP, and for the reduced lung compliance, suggests the intervention of active mechanisms. Acute changes of left heart and pul- 
monary venous pressures-besides producing the passive effects on PVR, distribution of blood flow, and lung mechanics that have been well documented in animal studies $(45,48,56,62,71,73-$ 76) - thus appear associated with active phenomena that increase the stiffness of the pulmonary vasculature and the lung as a whole.

Little information can be derived from this study on the possible mechanisms responsible for the observed behavior of PVD, PVR, and SLC after acute TBV expansion.

It might be supposed that the pulmonary vessels develop active tension as a response to quick stretch, i.e., to increased transmural pressure, according to the myogenic theory of autoregulation of blood flow (77). Although this possibility cannot be ruled out, the rate of stretch in the present study is much lower than that required to elicit an active response on isolated vascular smooth muscle (78). A further reservation concerns the larger pulmonary vessels, since a large vessel is considered a multiunit smooth muscle controlled by its nerves rather than by myogenic reflexes (78).

The reduction of arterial $\mathrm{Po}_{2}$, which is very likely due to inequalities of the lung ventilationperfusion ratio after dextran infusion, should not be responsible, on the basis of present evidence (79), for any increase of vascular smooth muscle tone.

It may then be suggested that the behavior of PVD, PVR, and SLC after dextran infusion is under the influence of a reflex mechanism.

The changes of PVD and PVR after the injection of atropine appear consonant with this suggestion for the following reasons: 1) Relaxation resulting from the parasympatholytic action of atropine is probably important for the bronchial musculature, but, on the basis of present knowledge (80), cannot be postulated for the human lung vessels. Even a direct action of atropine on pulmonary vessels appears unlikely, since no evidence has been collected in man or dog that indicates pulmonary vasodilatation after atropine administration (81-83). 2) Relaxation of pulmonary vessels after atropine does not seem ascribable to ganglionic blockade, since this activity of the drug requires doses much larger than those employed in the present study $(84,85)$. 3) On the other hand, after dextran infusion the stroke work of the left ventricle is $65 \mathrm{~g}-\mathrm{m}$ per beat per $\mathrm{m}^{2}$ with a LVEDP of $16 \mathrm{~mm} \mathrm{Hg}$, whereas after atropine the stroke work is $67 \mathrm{~g}-\mathrm{m}$ per beat per $\mathrm{m}^{2}$ with a LVEDP of $10 \mathrm{~mm} \mathrm{Hg}(86)$. This enhancement of the left ventricular performance may be interpreted-especially on the basis of some recent evidence of a tonic negative inotropic influence of the vagus nerves upon mammalian ventricular myocardium $(87,88)$-as the result of the parasympatholytic activity of the drug on the ventricle, and it may be considered at the origin of the pressure decrease which, in turn, may interrupt the reflex mechanism suggested above. Finally, 4) it cannot be excluded that the fall of end-diastolic pressure of both ventricles after atropine (86) is due to peripheral and splanchnic venous pooling of blood, with consequent relief of heart congestion and improvement of ventricular function, but Horsley and Eckstein found diminished forearm venous volume and increased venous tone after intravenous injection of $2 \mathrm{mg}$ of atropine sulfate in normal subjects; this response was not altered after inflation of an antigravity suit over the abdomen and the lower limbs (89).

\section{Summary}

The distensibility of the pulmonary circulation was studied in 17 subjects, all but one of whom had normal pulmonary circulation. They were studied in the supine position after dextran infusion and subsequent atropine injection. In a separate group of five subjects, lung mechanics were investigated under the same conditions. An average of $1,100 \mathrm{ml}$ of a $6 \%$ solution of dextran in saline was infused into each subject at a mean rate of $54 \mathrm{ml}$ per minute.

The acute expansion of total blood volume caused a striking elevation of the intravascular pressures throughout the central circulation, including the left ventricular end-diastolic pressure, with practically unchanged esophageal pressure. This pressure rise is accompanied by a modest increment of the stroke volume and the pulmonary blood volume. The ratio of change in volume to change in mean intravascular pressure in the pulmonary circulation as a whole was, on the average, $5 \mathrm{ml}$ per $\mathrm{m}^{2}$ per $\mathrm{mm} \mathrm{Hg}$. The pressure-volume relationship of the pulmonary vasculature after dextran appears to reflect a lower distensibility 
than that existing in the control state and after atropine injection. The pulmonary vascular resistances showed a small statistically insignificant fall. This behavior in the face of a marked increase of mean pulmonary wedge pressure suggests that the resistance vessels are less distensible. The lung compliance showed a modest but significant reduction.

The injection of atropine was followed by a decline of the central intravascular pressures, including the left ventricular end-diastolic pressure. The esophageal pressure at the level of the functional residual capacity did not show important variations. The stroke volume and the pulmonary blood volume were increased with respect to the control values and, to a lesser extent, even with respect to the postinfusion values. The ratio of change in volume to change in pressure with respect to control values was, on the average, 23 $\mathrm{ml}$ per $\mathrm{m}^{2}$ per $\mathrm{mm} \mathrm{Hg}$ for the entire pulmonary vasculature. The pulmonary vascular resistances fell significantly with respect to both the control and postinfusion levels. Consideration of the pressure-volume curve of the pulmonary circulation and of the relationship between pulmonary vascular resistances and intravascular pressure suggests that, after atropine, the distensibility of the pulmonary circulation as a whole and of the resistance vessels is considerably greater than that observed after dextran infusion and is close to the control value. The lung compliance showed a remarkable increase over both the control and postinfusion levels.

We suggest that the variations of pulmonary vascular distensibility and lung compliance after dextran infusion and subsequent atropine injection are mainly due to changes of the pulmonary vascular and parenchymal smooth muscle tone.

By exclusion of other possible mechanisms, we may advance the hypothesis that a reflex may be responsible for the above changes. Accordingly, and since no direct muscular or parasympatholytic dilating action of atropine on the pulmonary vasculature is at present recognized, we suggest that the effect of atropine on the pulmonary vessels is mediated through a reduction of the intravascular pressure, which is ascribed, in turn, to the parasympatholytic action of the drug that apparently improves the ventricular performance under these experimental circumstances.

\section{References}

1. Milnor, W. R., A. D. Jose, and C. J. McGaff. Pulmonary vascular volume, resistance, and compliance in man. Circulation 1960, 22, 130.

2. Dock, D. S., W. L. Kraus, L. B. McGuire, J. W. Hyland, F. W. Haynes, and L. Dexter. The pulmonary blood volume in man. $\mathrm{J}$. clin. Invest. 1961, 40, 317.

3. Oakley, C., G. Glick, M. N. Luria, B. F. Schreiner, Jr., and P. N. Yu. Some regulatory mechanisms of the human pulmonary vascular bed. Circulation 1962, 26, 917.

4. McGaff, C. J., G. C. Roveti, E. Glassman, and W. R. Milnor. The pulmonary blood volume in rheumatic heart disease and its alteration by isoproterenol. Circulation 1963, 27, 77.

5. Varnauskas, E., S. А̊. Forsberg, J. Widimsky, and S. Paulin. Pulmonary blood volume and its relation to pulmonary hemodynamics in cardiac patients. Acta med. scand. 1963, 173, 529.

6. Forsberg, S. $\AA$. Pulmonary blood volume in man. A study using the double indicator technique in patients with cardiovascular disease. Acta med. scand. 1964, suppl. 410.

7. West, J. B., C. T. Dollery, and B. E. Heard. Increased vascular resistance in the lower zone of the lung caused by perivascular œdema. Lancet 1964, 2, 181.

8. Dawson, A., K. Kaneko, and M. McGregor. Regional lung function in patients with mitral stenosis studied with xenon ${ }^{133}$ during air and oxygen breathing. J. clin. Invest. 1965, 44, 999.

9. Harris, P., and D. Heath. The Human Pulmonary Circulation. Edinburgh and London, E. \& S. Livingstone, 1962, p. 108.

10. McMichael, J., and E. Y. Sharpey-Schafer. Cardiac output in man by a direct Fick method. Effects of posture, venous pressure change, atropine and adrenaline. Brit. Heart J. 1944, 6, 33.

11. Weissler, A. M., J. J. Leonard, and J. V. Warren. Effects of posture and atropine on the cardiac output. J. clin. Invest. 1957, 36, 1656.

12. Gorlin, R. Studies on the regulation of the coronary circulation in man. I. Atropine-induced changes in cardiac rate. Amer. J. Med. 1958, 25, 37.

13. Berry, J. N., H. K. Thompson, Jr., D. E. Miller, and H. D. McIntosh. Changes in cardiac output, stroke volume, and central venous pressure induced by atropine in man. Amer. Heart J. 1959, 58, 204.

14. Gorten, R., J. C. Gunnells, A. M. Weissler, and E. A. Stead, Jr. Effects of atropine and isoproterenol on cardiac output, central venous pressure, and mean transit time of indicators placed at three different sites in the venous system. Circulat. Res. 1961, 9, 979.

15. Daly, W. J., J. C. Ross, and R. H. Behnke. The effect of changes in the pulmonary vascular bed produced by atropine, pulmonary engorgement, and positive-pressure breathing on diffusing and 
mechanical properties of the lung. $\mathrm{J}$. clin. Invest. 1963, 42, 1083.

16. Campbell, G. S., F. J. Haddy, W. L. Adams, and M. B. Visscher. Circulatory changes and pulmonary lesions in dogs following increased intracranial pressure and the effect of atropine upon such changes. Amer. J. Physiol. 1949, 158, 96.

17. Harrison, W., and A. A. Liebow. The effects of increased intracranial pressure on the pulmonary circulation in relation to pulmonary edema. Circulation 1952, 5, 824.

18. Seldinger, S. I. Catheter replacement of the needle in percutaneous arteriography. A new technique. Acta radiol. (Stockh.) 1953, 39, 368.

19. Chaplin, H., P. L. Mollison, and H. Vetter. The body/venous hematocrit ratio: its constancy over a wide hematocrit range. J. clin. Invest. 1953, 32, 1309.

20. Donato, L., C. Giuntini, M. L. Lewis, J. Durand, D. F. Rochester, R. M. Harvey, and A. Cournand. Quantitative radiocardiography. I. Theoretical considerations. Circulation 1962, 26, 174.

21. Donato, L., D. F. Rochester, M. L. Lewis, J. Durand, J. O. Parker, and R. M. Harvey. Quantitative radiocardiography. II. Technic and analysis of curves. Circulation 1962, 26, 183.

22. Lewis, M. L., C. Giuntini, L. Donato, R. M. Harvey, and A. Cournand. Quantitative radiocardiography. III. Results and validation of theory and method. Circulation 1962, 26, 189.

23. Giuntini, C., M. L. Lewis, A. Sales Luis, and R. M. Harvey. A study of the pulmonary blood volume in man by quantitative radiocardiography. J. clin. Invest. 1963, 42, 1589.

24. McNeely, W. F., and M. A. Gravallese, Jr. Measurement of cardiac output by dye dilution technique: use of an "integrated" sample collection in calibration of the photometric instrument. J. appl. Physiol. 1954, 7, 55.

25. Rescigno, A., and G. Segre. La Cinetica dei Farmaci e dei Traccianti Radioattivi. Turin, Boringhieri, 1961, p. 112.

26. Engelberg, J., and A. B. DuBois. Mechanics of pulmonary circulation in isolated rabbit lungs. Amer. J. Physiol. 1959, 196, 401.

27. Sarnoff, S. J., and E. Berglund. Pressure-volume characteristics and stress relaxation in the pulmonary vascular bed of the dog. Amer. J. Physiol. 1952, 171, 238.

28. Sarnoff, S. J., E. Berglund, and L. C. Sarnoff. Neurohemodynamics of pulmonary edema. III. Estimated changes in pulmonary blood volume accompanying systemic vasoconstriction and vasodilation. J. appl. Physiol. 1953, 5, 367.

29. Fishman, A. P. Dynamics of the pulmonary circulation in Handbook of Physiology, W. F. Hamilton and P. Dow, Eds. Washington, American Physiological Society, 1963, section 2, vol. 2, p. 1667.

30. Milic-Emili, J., J. Mead, and J. M. Turner. Topography of esophageal pressure as a function of posture in man. J. appl. Physiol. 1964, 19, 212.
31. Milic-Emili, J., J. Mead, J. M. Turner, and E. M. Glauser. Improved technique for estimating pleural pressure from esophageal balloons. J. appl. Physiol. 1964, 19, 207.

32. Ferris, B. G., Jr., and D. S. Pollard. Effect of deep and quiet breathing on pulmonary compliance in man. J. clin. Invest. 1960, 39, 143.

33. Cavallini, D. Le Emoglobine. Rome, Il Pensiero Scientifico, 1958, p. 187.

34. Lison, L. Statistica Applicata alla Biologia Sperimentale. Milan, Ambrosiana, 1961, p. 115.

35. Witham, A. C., J. W. Fleming, and W. L. Bloom. The effect of the intravenous administration of dextran on cardiac output and other circulatory dynamics. J. clin. Invest. 1951, 30, 897.

36. Fleming, J. W., and W. L. Bloom. Further observations on the hemodynamic effect of plasma volume expansion by dextran. J. clin. Invest. 1957, $36,1233$.

37. Schnabel, T. G., Jr., H. Eliasch, B. Thomasson, and L. Werkö. The effect of experimentally induced hypervolemia on cardiac function in normal subjects and patients with mitral stenosis. J. clin. Invest. 1959, 38, 117.

38. Fowler, N. O. Plasma substitutes in Handbook of Physiology, W. F. Hamilton and P. Dow, Eds. Washington, American Physiological Society, 1962, section 2, vol. 1, p. 63.

39. Warren, J. V., E. S. Brannon, H. S. Weens, and E. A. Stead, Jr. Effect of increasing blood volume and right atrial pressure on the circulation of normal subjects by intravenous infusions. Amer. J. Med. 1948, 4, 193.

40. Doyle, J. T., J. S. Wilson, E. H. Estes, and J. V. Warren. The effect of intravenous infusions of physiologic saline solution on the pulmonary arterial and pulmonary capillary pressure in man. J. clin. Invest. 1951, 30, 345.

41. Fowler, N. O., W. L. Bloom, and J. A. Ward. Hemodynamic effects of hypervolemia with and without anemia. Circulat. Res. 1958, 6, 163.

42. Frye, R. L., and E. Braunwald. Studies on Starling's law of the heart. I. The circulatory response to acute hypervolemia and its modification by ganglionic blockade. J. clin. Invest. 1960, 39, 1043.

43. Maxwell, G. M., R. B. Elliott, and E. Robertson. Observations on the effect of induced hypervolaemia upon the general and coronary hæmodynamics of the intact animal. Clin. Sci. 1964, 26, 61.

44. De Freitas, F. M., E. Z. Faraco, D. F. de Azevedo, J. Zaduchliver, and I. Lewin. Behavior of normal pulmonary circulation during changes of total blood volume in man. J. clin. Invest. 1965, 44, 366.

45. Haddy, F. J., and G. S. Campbell. Pulmonary vascular resistance in anesthetised dogs. Amer. J. Physiol. 1953, 172, 747.

46. Varnauskas, E., M. Korsgren, P. Houk, and I. Prérovský. Hemodynamic effects of rheomacrodex. Scand. J. clin. Lab. Invest. 1965 (suppl. 86), p. 81. 
47. Sjöstrand, T. Volume and distribution of blood and their significance in regulating the circulation. Physiol. Rev. 1953, 33, 202.

48. Borst, H. G., M. McGregor, J. L. Whittenberger, and E. Berglund. Influence of pulmonary arterial and left atrial pressures on pulmonary vascular resistance. Circulat. Res. 1956, 4, 393.

49. Borst, H. G., E. Berglund, and M. McGregor. The effects of pharmacologic agents on the pulmonary circulation in the dog. Studies on epinephrine, nor-epinephrine, 5-hydroxytryptamine, acetylcholine, histamine and aminophylline. J. clin. Invest. 1957, 36, 669.

50. Doyle, J. T., R. A. Lee, and E. B. Kelly. Observations on the elasticity of the pulmonary vasculature in man. Amer. Heart J. 1952, 44, 565.

51. West, J. B., C. T. Dollery, and B. E. Heard. Increased pulmonary vascular resistance in the dependent zone of the isolated dog lung caused by perivascular edema. Circulat. Res. 1965, 17, 191.

52. Guyton, A. C., and A. W. Lindsey. Effect of elevated left atrial pressure and decreased plasma protein concentration on the development of pulmonary edema. Circulat. Res. 1959, 7, 649.

53. Levine, O. R., R. B. Mellins, and A. P. Fishman. Quantitative assessment of pulmonary edema. Circulat. Res. 1965, 17, 414.

54. Ezekiel, M., and K. A. Fox. Methods of Correlation and Regression Analysis, 3rd ed. New York, John Wiley and Sons, 1959, p. 103.

55. Pearce, M. L., J. Yamashita, and J. Beazell. Measurement of pulmonary edema. Circulat. Res. 1965, $16,482$.

56. Frank, N. R., E. P. Radford, Jr., and J. L. Whittenberger. Static volume-pressure interrelations of the lungs and pulmonary blood vessels in excised cats' lungs. J. appl. Physiol. 1959, 14, 167.

57. Sancetta, S. M., and L. Rakita. Response of pulmonary artery pressure and total pulmonary resistance of untrained, convalescent man to prolonged mild steady state exercise. J. clin. Invest. 1957, 36, 1138.

58. Widimsky, J., E. Berglund, and R. Malmberg. Effect of repeated exercise on the lesser circulation. J. appl. Physiol. 1963, 18, 983.

59. Seaman, G. V. F., W. Hissen, L. Lino, and R. L. Swank. Physico-chemical changes in blood arising from dextran infusions. Clin. Sci. 1965, 29, 293.

60. Said, S. I., M. E. Avery, R. K. Davis, C. M. Banerjee, and M. El-Gohary. Pulmonary surface activity in induced pulmonary edema. J. clin. Invest. $1965,44,458$.

61. Carlill, S. D., H. N. Duke, and M. Jones. Some observations on pulmonary haemodynamics in the cat. J. Physiol. (Lond.) 1957, 136, 112.

62. Patel, D. J., A. J. Mallos, and F. M. de Freitas. Importance of transmural pressure and lung volume in evaluating drug effect on pulmonary vascular tone. Circulat. Res. 1961, 9, 1217.
63. Roughton, F. J. W., and R. E. Forster. Relative importance of diffusion and chemical reaction rates in determining rate of exchange of gases in the human lung, with special reference to true diffusing capacity of pulmonary membrane and volume of blood in the lung capillaries. J. appl. Physiol. 1957, 11, 290.

64. Lawson, W. H., Jr., H. N. Duke, R. W. Hyde, and R. E. Forster. Relationship of pulmonary arterial and venous pressure to diffusing capacity. J. appl. Physiol. 1964, 19, 381.

65. Daly, W. J., S. T. Giammona, and J. C. Ross. The "pressure-volume relationship" of the normal pulmonary capillary bed. J. clin. Invest. 1965, 44, 1261.

66. Pearce, M. L., H. Nagano, and N. C. Staub. Acute pulmonary edema due to elevation of pulmonary capillary pressure. Clin. Res. 1964, 12, 121.

67. Bondurant, S., J. B. Hickam, and J. K. Isley. Pulmonary and circulatory effects of acute pulmonary vascular engorgement in normal subjects. J. clin. Invest. 1957, 36, 59.

68. Bondurant, S., J. Mead, and C. D. Cook. A reevaluation of effects of acute central congestion on pulmonary compliance in normal subjects. J. appl. Physiol. 1960, 15, 875.

69. Daly, W. J., and S. Bondurant. Direct measurement of respiratory pleural pressure changes in normal man. J. appl. Physiol. 1963, 18, 513.

70. Clements, J. A., R. F. Hustead, R. P. Johnson, and I. Gribetz. Pulmonary surface tension and alveolar stability. J. appl. Physiol. 1961, 16, 444.

71. Cook, C. D., J. Mead, G. L. Schreiner, N. R. Frank, and J. M. Craig. Pulmonary mechanics during induced pulmonary edema in anesthetized dogs. J. appl. Physiol. 1959, 14, 177.

72. Yoshida, S. Effects of bronchoactive agents on static pressure-volume characteristics of dog lungs. Amer. J. Physiol. 1964, 206, 321.

73. Borst, H. G., E. Berglund, J. L. Whittenberger, J. Mead, M. McGregor, and C. Collier. The effect of pulmonary vascular pressures on the mechanical properties of the lungs of anesthetized dogs. J. clin. Invest. 1957, 36, 1708.

74. Frank, N. R. Influence of acute pulmonary vascular congestion on recoiling force of excised cats' lung. J. appl. Physiol. 1959, 14, 905.

75. Permutt, S., B. Bromberger-Barnea, and H. N. Bane. Alveolar pressure, pulmonary venous pressure, and the vascular waterfall. Med. thorac. 1962, $19,239$.

76. West, J. B., C. T. Dollery, and A. Naimark. Distribution of blood flow in isolated lung; relation to vascular and alveolar pressures. J. appl. Physiol. $1964,19,713$.

77. Folkow, B. Transmural pressure and vascular tonesome aspects of an old controversy. Arch. int. Pharmacodyn. 1962, 139, 455. 
78. Sparks, H. V., Jr. Effect of quick stretch on isolated vascular smooth muscle. Circulat. Res. 1964, 15 (suppl. 1), p. 254.

79. Enson, Y., C. Giuntini, M. L. Lewis, T. Q. Morris, M. I. Ferrer, and R. M. Harvey. The influence of hydrogen ion concentration and hypoxia on the pulmonary circulation. J. clin. Invest. 1964, 43, 1146.

80. Aviado, D. M. The Lung Circulation. Oxford, Pergamon, 1965, vol. 1, pp. 343-344.

81. Gorlin, R., I. K. R. McMillan, W. E. Medd, M. B. Matthews, and R. Daley. Dynamics of the circulation in aortic valvular disease. Amer. J. Med. 1955, 18, 855.

82. Segel, N., P. Harris, and J. M. Bishop. The effects of synthetic hypertensin on the systemic and pulmonary circulations in man. Clin. Sci. 1960, 20, 49.

83. Morkin, E., O. R. Levine, and A. P. Fishman. Pulmonary capillary flow pulse and the site of pulmonary vasoconstriction in the dog. Circulat. Res. 1964, 15, 146.
84. Marrazzi, A. Electrical studies on the pharmacology of autonomic synapses. I. The action of parasympathomimetic drugs on sympathetic ganglia. J. Pharmacol. exp. Ther. 1939, 65, 18.

85. Cahen, R. L., and K. M. Tvede. Action of atropine on sympathetic ganglia. Arch. int. Pharmacodyn. 1953, 94, 248.

86. Giuntini, C., A. Maseri, M. Mariani, C. Contini, and L. Donato. Right and left ventricular performances as modified by dextran infusion and subsequent atropine injection in normal subjects. In preparation.

87. DeGeest, H., M. N. Levy, H. Zieske, and R. I. Lipman. Depression of ventricular contractility by stimulation of the vagus nerves. Circulat. Res. 1965, 17, 222.

88. Levy, M. N., M. Ng, R. I. Lipman, and H. Zieske. Vagus nerves and baroreceptor control of ventricular performance. Circulat. Res. 1966, 18, 101.

89. Horsley, A. W., and J. W. Eckstein. Pressure-volume changes in human forearm veins after atropine administration. Proc. Soc. exp. Biol. (N. Y.) 1959, 100, 822. 